\title{
Analysis of Microbiological Culture Specimens in Shree Birendra Hospital, Chhauni
}

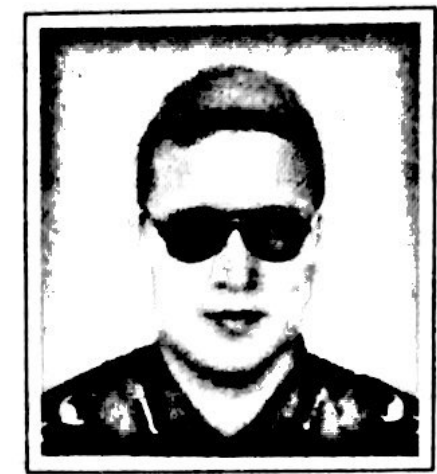

Abstract

This is a retrospective study of microbiological culture specimens processed between Baishakh 059 to Chaitra 059 over a span of one year (May-April 2003). During this period a total of 9430 samples were asked for culture and 1948 i.e. $20.6 \%$ showed growth. This study showed that commonest specimen was blood culture for salmonella (66.5\%) which was positive in 1009 (16.2\%) of cases. Other common specimens were urine, pus and sputum showing $55.31 \%$, $22.0 \%$ and $7.5 \%$ respectively.

This study also showed increased demand of blood culture samples in month of Ashad, Shrawan and Bhadra. However, nonblood culture samples were almost uniform in distribution through out the year (average $261 /$ month).

The commonest organisms isolated in urine, pus and sputum culture were E. coli in $79.5 \%$, staphylococcus aureus in $66.2 \%$ and Klebsiella and E. coli in $36.5 \%$ each respectively.

\section{Key Words :}

Microbiology specimens, culture, salmonella, urinary tract infections, pus, sputum.

\author{
Dr. Jagat S. Pandey, MBBS, MD \\ Consultant Pathologist
}

\section{Introduction}

The causative factors of disease namely agent, host and environment form an epidemiological triad. The biologic agents like viruses, bacteria, fungi, protozoa, rickettsia etc. have high importance leading to infectious diseases in medical practice in the past, present as well as in the future because of their enormous frequency and contagiousness. However, development in sanitary engineering, immunizations, vector control, early diagnosis and specific chemotherapy have modified the situation favorably. One should not forget that these diseases are easily prevented and more easily cured than any other major groups of disorders.

Culture helps in isolation of etiological agent by cultivation in artificial media though it is time consuming and complex. It provides the most definite diagnosis. However, proper specimen collection, rapid transportation to the laboratory and proper correlation of microbiological report with the patient's symptoms are some important factors. This study will throw some light upon the types of culture specimen, distribution in different months and different aetiological agents in the biggest Army Hospital (380 bedded) situated in Kathmandu which serves people from all over the country. I feel literature is lacking on this aspect in Nepal. 


\section{Materials and Methods}

This study was carried out in Birendra Hospital, Chhauni. All culture specimens along with their bacterial isolates (if positive) were noted from the registers of microbiology section from Baishakh 059 to Chaitra 059 B.S. (May 2003 to April 2003).

Culture of midstream sample voided in sterile bottle was done on $5 \%$ blood agar and MacConkey agar plate with inoculating loop of standard dimension. The culture plates were incubated overnight at $37^{\circ} \mathrm{c}$. Samples showing $10^{5}$ or more organism per $\mathrm{ml}$ of uncentrifuged urine were taken as significant. Identification of significant isolates were done by using standard microbiological techniques.

For collection of blood samples standard aseptic techniques were followed. In $10 \mathrm{ml}$ broth 2 $\mathrm{ml}$ of blood was poured at the bedside with aseptic precautions and were incubated at $37^{\circ} \mathrm{c}$. Incubation was continued in seven days unless the visible growth was obtained earlier. The subculture of positive culture was done on blood agar and MacConkey agar from those broth which showed organism. The MacConkey and blood agar plates were incubated at $37^{\circ} \mathrm{c}$ for 24 hours. Identification of bacteria from positive culture plates was done with the use of standard microbilogical techniques which included colony morphology, staining reactions and biochemical properties.

Similarly respective standard techniques were followed for other specimens in collection, processing and inoculation. After appropriate time of incubation, the culture plates were observed for significant growth of the organism.

\section{Results}

\begin{tabular}{|c|c|c|}
\hline \multicolumn{3}{|c|}{$\begin{array}{c}\text { Table - } 1 \\
\text { Total Number of Culture Samples }\end{array}$} \\
\hline Types of specimen & No & Percentage \\
\hline Blood Culture & 6250 & 66.62 \\
\hline Nonblood Culture & 3180 & 33.72 \\
\hline Total & 9430 & 100 \\
\hline
\end{tabular}

This table shows that blood culture sample was the commonest sample $(66.5 \%)$ and there were total of 9430 culture specimens received in one year.

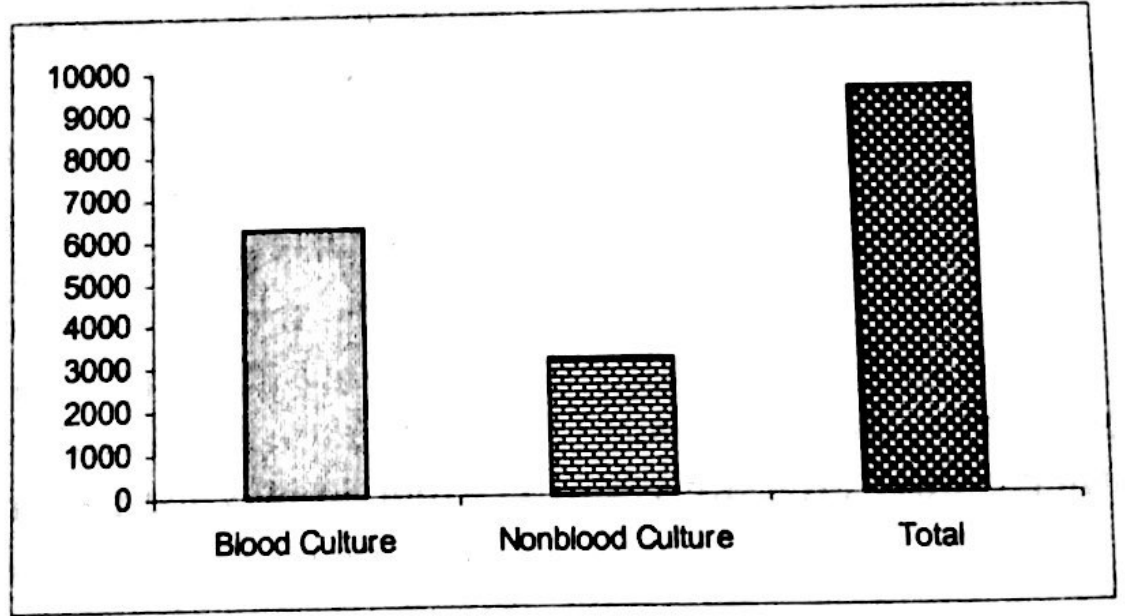


Table - 2

Types of Blood Culture Samples and Culture Positivity

\begin{tabular}{|l|r|r|c|c|}
\hline & No. of Samples & Percentage & Positive No & $\begin{array}{l}\text { Positive } \\
\text { Percentage }\end{array}$ \\
\hline $\begin{array}{l}\text { Blood Culture for } \\
\text { Salmonella }\end{array}$ & 6240 & 99.8 & 1009 & 16.14 \\
\hline $\begin{array}{l}\text { Blood Culture for } \\
\text { non Salmonella }\end{array}$ & 10 & 0.02 & 0 & 0 \\
\hline Total Samples & $\mathbf{6 2 5 0}$ & $\mathbf{1 0 0}$ & $\mathbf{1 0 0 9}$ & $\mathbf{1 6 . 1 4}$ \\
\hline
\end{tabular}

There was almost always demand of culture for salmonella organism amongst samples received for blood culture. Among 6240 samples of culture, $16.14 \%$ were found to be positive.

Table - 3

Enteric Fever in Different Groups of People

\begin{tabular}{|l|c|c|c|c|}
\hline & $\begin{array}{c}\text { Total No of } \\
\text { Samples }\end{array}$ & $\begin{array}{c}\text { No of Positive } \\
\text { Samples }\end{array}$ & Percent & Chi $^{\mathbf{2}} \mathbf{P}$ Value \\
\hline Officers & 151 & 10 & 6.6 & \\
\hline Non officers & 2283 & 549 & 24.0 & 0.000 \\
\hline Families & 3816 & 480 & 12.6 & \\
\hline Total & $\mathbf{6 2 5 0}$ & $\mathbf{1 0 0 9}$ & & \\
\hline
\end{tabular}

The table $\mathrm{C}$ depicts that non-officer and families have almost equal number of infection with enteric fever.

\section{Table - 4}

Types of Microbiological Samples other than Blood

\begin{tabular}{|l|c|c|c|r|}
\hline \multicolumn{1}{|c|}{ Types } & $\begin{array}{c}\text { No. of } \\
\text { Samples }\end{array}$ & $\begin{array}{c}\text { Percentage of } \\
\text { Non-Blood }\end{array}$ & $\begin{array}{c}\text { No of Positive } \\
\text { Samples }\end{array}$ & Percentage \\
\hline Unine & 1759 & 55.31 & 470 & 26.71 \\
Pus & 702 & 22.0 & 373 & 53.13 \\
Sputum & 227 & 7.1 & 76 & 33.48 \\
Throat Swab & 183 & 5.75 & 14 & 7.6 \\
Fluid & 111 & 3.4 & 1 & 0.9 \\
Stool & 60 & 1.8 & 0 & 0 \\
Drain Swab/ET Tube/ Cannula tips & 39 & 1.0 & 3 & 7.6 \\
CSF & 34 & 1.0 & 1 & 2.9 \\
AFB Culture & 28 & 0.88 & 2 & 7.1 \\
FNAC aspiration & 22 & 0.69 & 0 & 0 \\
Fungal Culture & 10 & 0.31 & 0 & 0 \\
High vag. swab & 4 & 0.12 & 1 & 25 \\
Bronchoalvcolar lavage & 1 & 0.13 & 0 & 0 \\
\hline Iotal & 3180 & 100 & 941 & 29.88 \\
\hline
\end{tabular}


As per this table first three common samples were found to be urine, pus and sputum beside blood culture and constitute $55.31 \%, 22.0 \%$ and $7.1 \%$ respectively. The least common culture sample was broncho-alveolar lavage $(0.3 \%)$. Maximum culture positivity was seen in pus culture (53\%) followed by sputum (33.48\%) and urine( $26.7 \%)$.

\begin{tabular}{|l|c|c|}
\hline \multicolumn{3}{|c|}{ Table - 5 } \\
\hline Name of Organism & No. of Positive Samples & Percentage \\
\hline Staph. aureus & 247 & 66.2 \\
E. Coli & 57 & 15.3 \\
Pseudomonas & 48 & 12.9 \\
Proteus & 12 & 3.2 \\
Citrobacter & 4 & 1.0 \\
Klebsiella & 3 & 0.8 \\
Providencia Species & 1 & 0.3 \\
Streptococcus & 1 & 0.3 \\
\hline Total & $\mathbf{3 7 3}$ & $\mathbf{1 0 0}$ \\
\hline
\end{tabular}

It depicts that Staph. aureus and E.coli are the first two common organisms $66.2 \%$ and $15.3 \%$ respectively in pus culture.

\begin{tabular}{|c|c|c|}
\hline \multicolumn{3}{|c|}{$\begin{array}{c}\text { Table - } 6 \\
\text { Types of Organism in Sputum Culture }\end{array}$} \\
\hline Name of Organism & No. of Positive Samples & Percentage \\
\hline Klebsiella & 27 & 35.5 \\
\hline E. Coli & 27 & 35.5 \\
\hline Pseudomonas & 16 & 21 \\
\hline Proteus & 3 & 4 \\
\hline Citrobacter & 3 & 4 \\
\hline Total & 76 & 100 \\
\hline
\end{tabular}

The table 6 shows that common isolates in sputum culture were klebsiella and E.coli 35.5\% each and least common isolates were proteus species and citrobacter $4 \%$ each.

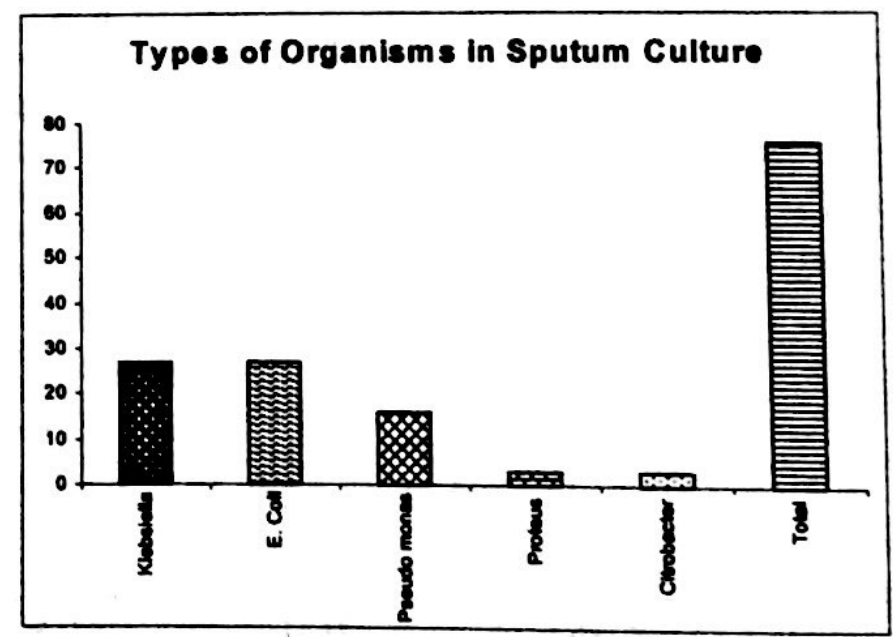




\section{Graph - 7}

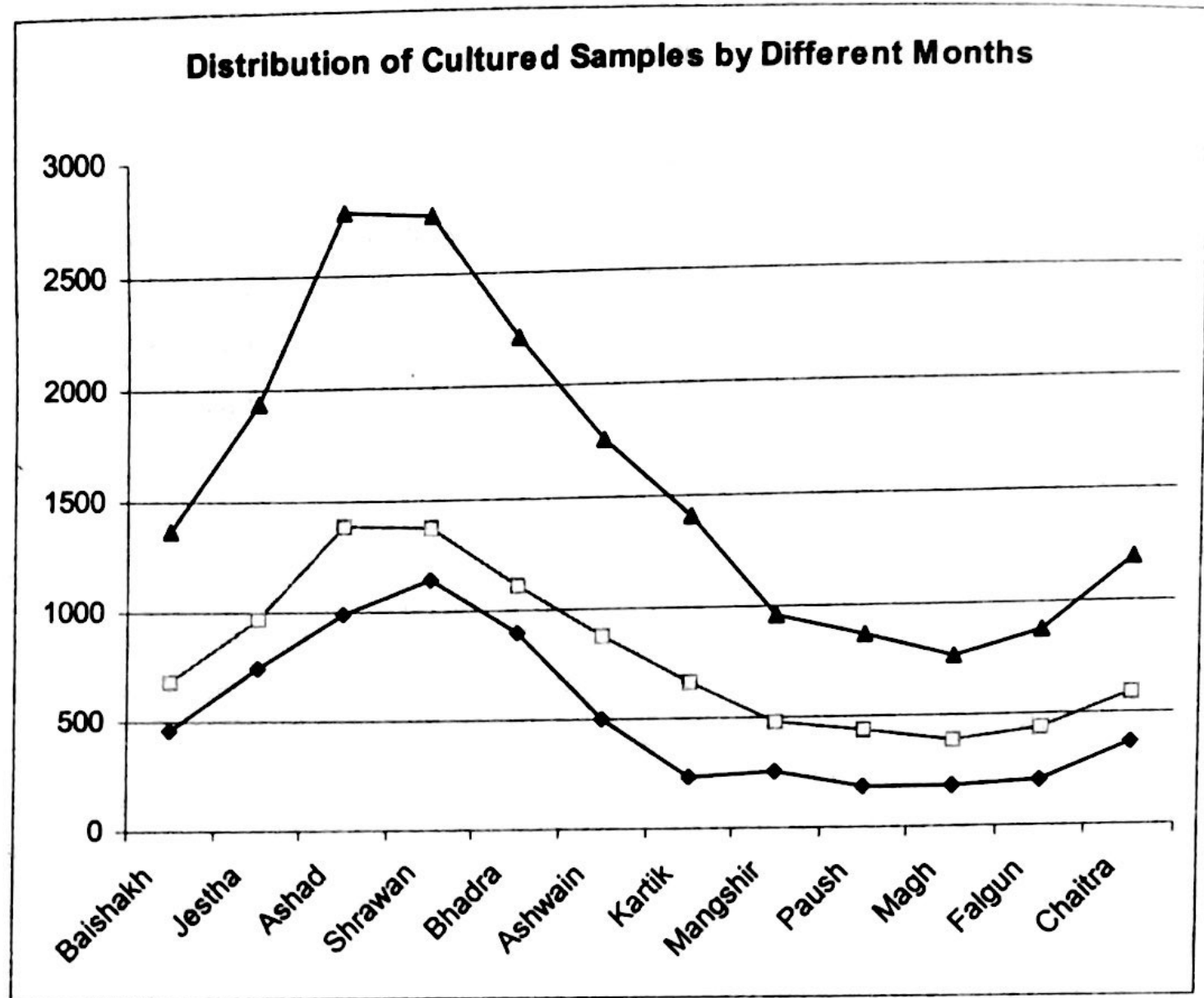

This Graph -7 shows increased blood culture sample demand in months of Ashad, Shrawan and Bhadra where as non-blood culture samples were more or less same.

\section{Discussion}

Infection has been one of the commonest causes of disease and death particularly in children'. It differs from other disease in few aspects like it is caused by a living micro-organism; it is communicable and most infections are potentially curable. Hence, culture specimens are one of the commonest investigation in microbiology department of any hospitals to find out aetiological agent of infection.

The results showed a total of 9430 culture samples in one year (2059 B.S.) with blood culture being the most demanded test (66.2\%). The result of blood culture showed $16.14 \%$ growth positivity which is slightly higher than the study carried out by Rai et.al. in TUTH $(15.31 \%)^{2}$. Their study showed Staph. aureus $(33.33 \%)$ being the commonest organism followed by Kleb. pneumoniae and S.typhi and S.paratyphi ,whereas this study showed salmonella species as the only organism isolated in blood culture. Another study carried out in TUTH by Banjade NR, and Pokheral $\mathrm{BM}^{3}$ showed staph aureus and salmonella typhi were commonest isolates $42.10 \%$ and $38.59 \%$ respectively. So these findings were different as far as bacteriological isolates were concerned and hence prevalence of enteric fever is highest in our hospital. 
Amongst nonblood samples, urine culture was the commonest specimen for investigation $(55.31 \%)$ followed by pus $(22 \%)$ and stool (7.2\%). In urine culture, E.coli was the commonest isolate $79.5 \%$ and citrobacter and Morganella morganii were the least common pathogens. The higher prevalence of E.coli seen was similar to many other studies done by various other workers. Rai et.al. ${ }^{2}$ showed $61.79 \%$ whereas Kulkarni et.al. (1986) ${ }^{4}$ in India showed E.coli as the principle isolate in urine.

The microbiology of pus samples showed Staph aureus $(66.2 \%)$ as the principle pathogen followed by E.coli (15.3\%). This finding was similar to findings of Rai $\mathrm{C}$ et.al. and Parajuli $\mathrm{K}^{3}$. In the case of sputum sample, only $7.1 \%$ showed significant growth of organisms and principle organism were Klebsilla species $35.5 \%$ and E.coli. Rai et.al. showed growth of $38.83 \%$, Shrestha ${ }^{6}$ showed $40 \%$ and Woodhead $25 \%$.The study of Rai et.al. showed Kleb. pneumoniae (25\%) followed by $\mathrm{H}$. influenzae and $\mathrm{Ps}$. aeruginosa (17.5\%) each and E.coli (15\%). In contrary to our study, Shrestha ${ }^{6}$ in 1995 isolated $\mathrm{H}$. influenzae $(39.3 \%)$ followed by Kleb. pneumonia $(15.5 \%)$.

In 1993, the study carried out by Macfarland et.al ${ }^{8}$ found that out of 206 adults patients Strepto. pneumoniae $30 \%$ was the commonest isolates followed by $\mathrm{H}$. influenzae $8 \%$. Similarly study carried out by Buccheri ${ }^{9}$ in Italy in $1983-1984$ in LRTI showed that $\mathrm{S}$. pneumoniae and $\mathrm{H}$. influnzae were common. Our results did not corelate with the above mentioned researchers probably because of different treatment modalities, geographical variations and economic status.

This study also showed that blood culture specimens were more demanded in the month of Ashad, Shrawan and Bhadra probably as it coincides with rainy season and there is an increase in the fly population ${ }^{11}$. The result also depicts that non-officers, families and officers have $24 \%, 12.57 \%$ and $6.6 \%$ positivity for enteric fever. These figures are statistically significant. Non-officers have higher rate because of poor hygiene, lower living standards, living in groups in barracks and they have to travel in different places frequently. Here, the positive cases in families are low, though they are about five times more in number than the regular army people. This is probably because all do not report to army hospital and they are more hygenic than their fellow men.

\section{Conclusion}

It is concluded that average culture specimen is 26 per day in a referral Army hospital situated in Kathmandu. Amongst total samples of 9430 , positive growth was seen in $20.67 \%$. Amongst the culture samples blood culture for salmonella was commonest (66.6\%) in which $16.14 \%$ were found to be positive. The figure shows that non-officers are positive for enteric fever in $24 \%$ of cases. This shows that we should 
upgrade their hygiene and living standards, drinking water supply and sanitation in the future to control their enteric fever problem. In a developing country like Nepal, culture specimen helps a lot to the clinician for treatment by giving a definitive diagnosis.

\section{Bibliography}

1. Christopher R. W. Edwards, Ian AD Bouchier. Diseases due to infections. Davidson's, Principle and Practice of Medicine. 16th ed, Churchill Livingstone. 1997; 96-201

2. C Rai, BM Pokhrel, AP Sharma. A Prospective Study on antibiotic sensitivity profile of the organisms associated with clinical infections among the patients attending T.U. Teaching Hospital. J of NAMLS 2001; 3: 13-16

3. NR Banjade, BM Pokhrel. Bacteriology of bacterimia/septicemia at Tribhuvan University Teching Hospital. J of NAMLS 2001; 21-30.

4. Kulkami MN, Guljar MB, Abdul A et al. In vitro antibiotic sensitivity pattern of microorganisms isolated from urine samples. Indian J com Microb Immunol Infect Dis 1986;7 (2\& 3):76-78

5. Parajuli K. Study of causative organisms from pus samples and its antibiotic sensitivity pattern. Tribhuvan University Kathmandu, Nepal, A dissertation 1997.

6. Shrestha B, Sharma AP, Pokhrel BM. Antibiotic sensitivity pattern of bacterial isolates from patients having lower respiratory tract infection: A hospital based study. J Nepal Med Assoc 1995:33:300-304.

7. Woodhead Mark. Antibiotics resistence in community acquired pneumonia. Brit J Hospital Med 1992;47(9):684-687.

8. Mac farlane JT, Colville A, Guion A et al. Prospective study of aetiology and outcome of adlt-LRTI in community Lancet 1993;341 (8844):511-514.

9. Buccheri GF;Ranado B; Violante B; Osenela M and Ferrigno D. Microbiological studies in patients with LRTI. Biological abstracts 1987; 83:8.

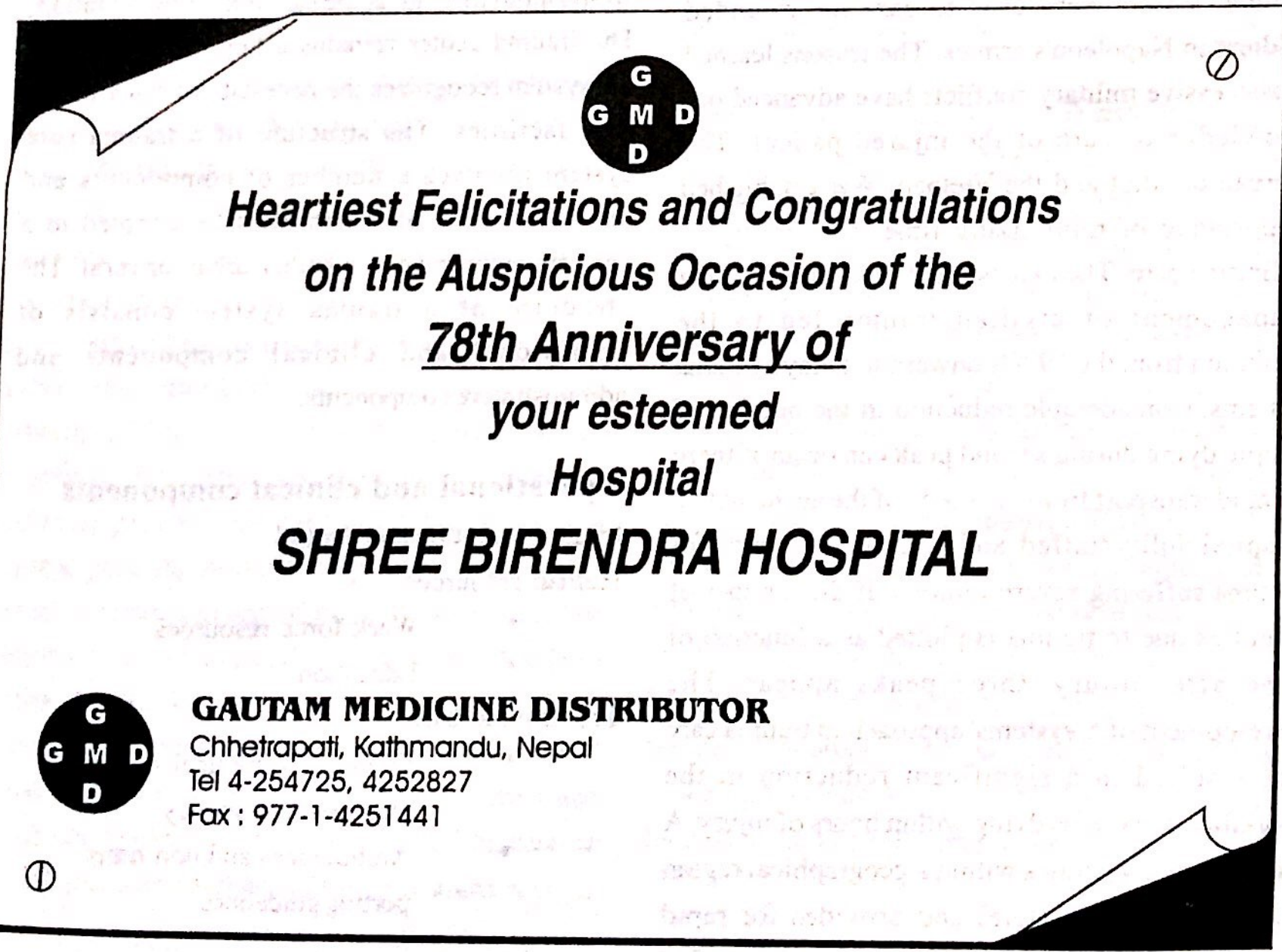

